\title{
International Migration of Skilled Workers with Endogenous Policies
}

\author{
Slobodan Djajić \\ Graduate Institute of International and Development Studies \\ Michael S. Michael \\ Department of Economics, University of Cyprus
}

\begin{abstract}
We study the interaction between the optimal immigration policy of a host country and education policy of a source country in a model of international migration of skilled workers. Acquisition of human capital is driven by the academic and career opportunities at home and abroad. Greater opportunities to migrate are found to increase the source country's net stock of human capital only under very stringent conditions concerning the shape of the utility function and of the production function for human capital, the country's emigration rate, and the international wage di $\leftarrow$ erential. We use the model to examine the e $\mathrm{e}^{\leftarrow}$ ects of technological improvements in the educational sector, changes in the academic curricula in the source country, and attitudes to immigration in the host country. Of key interest are the implications for the optimal spending on education in the source country and the optimal immigration quota of the host country.
\end{abstract}

(C) The Authors.

All rights reserved. No part of this paper may be reproduced without the permission of the authors. 


\title{
International Migration of Skilled Workers with Endogenous Policies
}

\author{
Slobodan Djajić* \\ and \\ Michael S. Michael ${ }^{\dagger}$
}

March 24, 2014

\begin{abstract}
We study the interaction between the optimal immigration policy of a host country and education policy of a source country in a model of international migration of skilled workers. Acquisition of human capital is driven by the academic and career opportunities at home and abroad. Greater opportunities to migrate are found to increase the source country's net stock of human capital only under very stringent conditions concerning the shape of the utility function and of the production function for human capital, the country's emigration rate, and the international wage differential. We use the model to examine the effects of technological improvements in the educational sector, changes in the academic curricula in the source country, and attitudes to immigration in the host country. Of key interest are the implications for the optimal spending on education in the source country and the optimal immigration quota of the host country.
\end{abstract}

JEL Classification: F22; J24; O15

Key Words: Migration of skilled workers, immigration policy, education policy

*Corresponding Author: Slobodan Djajić, Graduate Institute, 11A, Avenue de la Paix, CH-1202 Geneva, Switzerland, Tel.: (41) 22908 5934, Fax: (41) 22733 3049,e-mail: slobodandjajic@yahoo.com. This paper was initiated when Djajić was visiting the Department of Economics of the University of Cyprus. I wish to thank the Department for its hospitality and support.

${ }^{\dagger}$ Department of Economics, University of Cyprus, email: m.s.michael@ucy.ac.cy 


\section{Introduction}

Migration of skilled labor from the developing to the advanced countries has been the subject of extensive research over the last four decades. Efforts to measure these flows, including the works of Carrington and Detragiache (1998), Docquier and Marfouk (2006), and Beine, Docquier and Rapoport (2007), indicate that skilled emigration, as a proportion of the economy's skilled population, is particularly large in the case of relatively small developing countries. Island economies as well as countries in Central America, SubSaharan Africa, and South-East Asia are found to have the highest skilled-emigration rates. ${ }^{1}$ Rates of over $80 \%$ are reported for several Caribbean nations and they exceed $50 \%$ in many African countries (Docquier and Rapoport, 2012). Recent studies on the educational selectivity of migrants, such as the works of Grogger and Hanson (2011) and Belot and Hatton (2012), also point in the same direction: Migrants from the poor countries are strongly positively selected from among the source country's population.

Given that the cost of education and training represents a disproportionate financial burden for the developing countries (Lucas, 2005), the exodus of skilled workers can be expected to have an impact on their education policies (see Justman and Thisse, 1997, and Djajić, Michael, and Vinogradova, 2012). A strong confirmation of this is provided by Docquier, Faye, and Pestieau, (2008), who examine the question both theoretically and empirically. They uncover a negative relationship between education subsidies and skilled emigration rates based on the data covering 108 middle-income and low-income countries. Still, incentives for human capital accumulation in a source country depend not only on public subsidies to education, but also on other factors including migration opportunities. This is one of the key points to emerge from the extensive literature on migration of skilled workers and its implications for the source countries. ${ }^{2}$ There is

\footnotetext{
${ }^{1}$ See Commander et al. (2004) and Docquier and Rapoport $(2008$, 2012) for very useful surveys of the various issues and evidence related to the brain drain.

${ }^{2}$ Some of the early contributions to this literature include Bhagwati and Hamada (1974), Djajić (1989),
} 
by now abundant evidence that migration opportunities help stimulate human capital formation (see Beine, Docquier and Rapoport, 2001, 2008, 2010, Easterly and Nyarko, 2009, and Beine, Docquier and Oden-Defoort, 2011). Using data on 127 developing countries, Beine, Docquier and Rapoport (2008) find that a doubling of a country's emigration rate of highly-skilled workers is associated with a $5 \%$ increase in the stock of human capital possessed by its nationals. Using their point estimates, they perform counterfactual simulations to compute the number of skilled individuals remaining in the country after emigrants are netted out. Their findings suggest that under certain conditions the stimulus to skill formation may be strong enough to bring the economy's stock of human capital to a higher level in the post-migration equilibrium. Economies with a low emigration rate and a low level of human capital (examples of some large countries with these characteristics being Brazil, China, Egypt, India, and Indonesia) are likely to enjoy such a beneficial brain drain. Micro-level studies by Chand and Clemens (2008) and Gibson and McKenzies (2011) also find evidence of a positive impact of emigration on the net stock of human capital in a source country.

The present study contributes to this literature on the brain drain by analyzing the interaction between the optimal immigration policy of the host country and the optimal education policy of the source country in the context of a two-country model where the effort of students to accumulate human capital is driven by optimizing behavior with an eye on career opportunities at home and abroad. An important distinction between our framework of analysis and that of the earlier studies focusing on the optimal education policy of a source country is with respect to the conditions under which a potential migrant accumulates human capital. Previous contributions address the problem under the assumption that education is privately funded, with agents having access to credit

Miyagiwa (1991), Mountford (1997), Wong (1997), Stark et al. (1997), Vidal (1998), Wong and Yip (1999), Beine, Docquier and Rapoport (2001), Stark and Wang (2002), and Domingues Dos Santos and Postel-Vinay (2003). 
markets (as in Beine, Docquier and Rapoport, 2001, Stark and Wang, 2002, Docquier, Faye, and Pestieau, 2008, and Bertoli and Brücker, 2011), or facing liquidity constraints (as in Beine, Docquier and Rapoport, 2008 and Docquier and Rapoport, 2012), while the role of the authorities is to set the level at which they subsidize the optimallychosen private expenditures on education. We assume instead that only fully subsidized public education is available. This structure may be more fitting when considering the problem of investment in education in poor developing countries, where even informal credit markets for the purpose of funding private education are underdeveloped and where education is predominantly provided by the public sector free of charge. Instead of deciding on how much money to invest in the acquisition of human capital, students in our model optimally choose their study effort as a function of their academic and occupational opportunities, while the authorities choose the level of expenditures on education so as to maximize net national income. Another important feature of our model, which distinguishes it from those developed in the above-mentioned studies, is that we take the immigration policy of the host country to be endogenous. The host country chooses how many immigrants to admit, depending on its perceived marginal cost and benefit of hosting a foreign worker.

Our investigation proceeds in three steps. We begin by solving for the equilibrium levels of educational spending and students' effort in a "source" country under autarky. We subsequently open the economy to capital inflows and show that the benefits of hosting foreign capital extend beyond the positive impact on the productivity of labor. With endogenous education policy and students' effort, we find that under realistic assumptions the economy enjoys further benefits as it adjusts to a regime of international capital mobility. Finally, as we open the economy to international migration, this induces students to exert even greater effort to acquire skills. An expansion of migration opportunities is found to increase the economy's net stock of human capital provided that in 
the initial equilibrium (i) the emigration rate is low, (ii) the elasticity of the humancapital production function with respect to a student's effort is high, (iii) the degree of concavity of the utility function is low, and (iv) the international earnings differential is sufficiently large. Under such conditions an increase in recruitment of skilled workers by the host country has a large impact on the effort of students in school, as well as a large impact on their subsequent productivity at the workplace. The stock of human capital remaining in the source country and net output can then increase in spite of the fact that more skilled workers exit the economy. In this type of an environment, referred to as a "low-migration" equilibrium, it also pays for the authorities of the source country to raise educational expenditures in response to an increase in migration opportunities that are available to its citizens in the host country.

After setting up the model in Section 2, we examine in Section 3 the implications of (i) a reduction in the cost of providing educational services in the source country, (ii) a shift in preferences on immigration in the host country, and (iii) a change in the degree of international transferability of human capital. In all these exercises, our focus is on the amount of effort exerted by students in school, the optimal level of source-country spending on education, and the optimal immigration quota of the host country in the Nash equilibrium. Our model suggests that in the presence of endogenous immigration and education policies, technological improvements in the provision of educational services may contribute more to skill level convergence of graduates across developing countries than they do if immigration and education policies are exogenously given. We also find that changes in the academic curricula of the source country can play an important role in improving its welfare. In a "low-migration" equilibrium, adjustments to the curriculum that increase the international transferability of skills acquired in the source country are shown to improve the welfare of both economies. By contrast, in a "high-migration equilibrium", defined as an environment in which a higher emigration 
rate reduces the economy's net stock of human capital, an improvement in the welfare of the source country calls for a curriculum change that lowers the transferability of skills and reduces the welfare of the host country. We conclude the paper in Section 4, by highlighting its principal contributions.

\section{The Analytic Framework}

We consider a world consisting of two countries, advanced and developing, both producing a single commodity with the aid of capital and skilled labor. The advanced foreign country $(\mathrm{F})$ is assumed to have a more efficient technology of production, resulting in a higher productivity of skilled labor when compared with the source country $(\mathrm{S})$. The latter provides education to its citizens with the view of maximizing its GNP, net of expenditures on education. After completing studies, some of the graduates may be able to migrate to $\mathrm{F}$, depending on the regime governing international migration. Before considering the implications of labor mobility, however, let us begin by defining the environment facing individuals and the authorities in S under autarky.

\subsection{The Autarky Case}

Consider the problem of an individual in a closed economy. Her lifetime consists of two phases of given durations. In the first phase she is supported by her parents and has to decide on how to optimally divide her time, normalized to unity, between leisure, $l$, and study effort, $z$. The skills acquired in the first phase affect her income and consumption in the second phase. Utility is derived from leisure, $l$, in this first (formative) phase and consumption of commodities, $C$, in the second (career) phase according to a separable utility function $U(l, C)=v(l)+u(C)$. We adopt the standard assumptions: $v^{\prime}(l)>0$, $v^{\prime \prime}(l) \leq 0, u^{\prime}(C)>0$, and $u^{\prime \prime}(C)<0$. By investing more of her time in education, a 
student can acquire more skills, $H$, which allows for a higher income and consumption, $C$, in the second phase. More precisely,

$$
C(w, z, \varepsilon)=w H(z, \varepsilon),
$$

where $w$ is the real wage in S per unit of skill acquired by the student and $\varepsilon$ is the level of educational services dispensed by the authorities of the source country. Only public education is available and it is provided to students free of charge. We assume that $H_{z}>0, H_{\varepsilon}>0, H_{z z}<0, H_{\varepsilon \varepsilon}<0$, and $H_{z \varepsilon}>0$. There is full employment and perfect wage flexibility to clear the market for labor at all times.

The optimization problem of a student is to

$$
\max _{z} v(1-z)+u(w H(z, \varepsilon)),
$$

taking $w$ and $\varepsilon$ as given. The first-order condition reads:

$$
-v^{\prime}(1-z)+u^{\prime}(C) w H_{z}(z, \varepsilon)=0,
$$

which provides an implicit solution for the optimal study effort, $z$, as a function of $\varepsilon$ and the real market wage, $w$, per unit of skill. This relationship implies that the effect of the wage on study effort is positive, assuming that the elasticity of marginal utility of consumption, $\theta$, defined to be positive, is less than unity:

$$
\frac{\partial z}{\partial w}=\frac{\frac{u^{\prime}(C)}{w}(\theta-1) \frac{\partial C}{\partial z}}{v^{\prime \prime}(1-z)+u^{\prime \prime}(C)\left(\frac{\partial C}{\partial z}\right)^{2}+u^{\prime}(C) \frac{\partial^{2} C}{\partial z^{2}}}>0,
$$

as both the denominator and the numerator are then negative. On the basis of evidence documented in the literature risk aversion and labor supply behavior, we consider this 
to be the relevant case. ${ }^{3}$

$$
\frac{\partial z}{\partial \varepsilon}=-\frac{u^{\prime \prime}(C) \frac{\partial C}{\partial z} \frac{\partial C}{\partial \varepsilon}+u^{\prime}(C) \frac{\partial^{2} C}{\partial z \partial \varepsilon}}{v^{\prime \prime}(1-z)+u^{\prime \prime}(C)\left(\frac{\partial C}{\partial z}\right)^{2}+u^{\prime}(C) \frac{\partial^{2} C}{\partial z^{2}}},
$$

where the denominator is unambiguously negative, while the two terms in the numerator have conflicting signs: both $\frac{\partial C}{\partial z} \frac{\partial C}{\partial \varepsilon}$ and $\frac{\partial^{2} C}{\partial z \partial \varepsilon}$ are positive, while $u^{\prime \prime}(C)<0$ and $u^{\prime}(C)>0$. Let us consider the case of iso-elastic utility functions

$$
v(1-z)=\frac{(1-z)^{(1-\chi)}}{(1-\chi)}, \quad u(C)=\frac{C^{(1-\theta)}}{(1-\theta)}
$$

and assume that

$$
H(z, \varepsilon)=\mu \varepsilon^{\beta} z^{\gamma}
$$

where $\mu>0$ is a parameter reflecting the efficiency of the skill-formation technology, $\beta \in(0,1), \gamma \in(0,1)$, and $\beta+\gamma<1 .{ }^{4}$ We can then write

$$
\frac{\partial z}{\partial \varepsilon}=\frac{z(1-\theta) \beta}{\varepsilon\left[1-\gamma(1-\theta)+\chi \frac{z}{1-z}\right]}>0
$$

indicating that if the authorities choose to provide a higher $\varepsilon$, this triggers more effort on the part of students. As one would expect, the elasticity of $z$ with respect to $\varepsilon$ is

\footnotetext{
${ }^{3}$ Estimates of $\theta$ vary significantly, depending on the data used and the empirical strategy. Chetty (2006) examines some of the factors that explain this wide range of estimates. He reports that the mean estimate in the literature is $\theta=0.71$, while noting that studies which combine the benefits of exogenous variation with the structural lifecycle approach, such as Blundell, Duncan, and Meghir (1998), with its estimate of $\theta=0.93$, provide perhaps the most credible microeconomic estimates.

${ }^{4}$ There is an extensive literature on the positive relationship between educational inputs that correspond to $\varepsilon$ (such as teacher quality and class size) and the skill level of students (reflected in their test scores and even subsequent earnings). By contrast, we have not been able to find documented evidence on the relationship between study effort of students taking part in a given educational program and their productivity or earnings after graduation, which would provide us with information regarding $\gamma$. The impact of study effort is obviously difficult to measure in a student population as it consists of inputs such as time and the degree of mental concentration, while its effectiveness depends on a range of other parameters and personal characteristics of a student.
} 
positively related to the elasticity of $H(z, \varepsilon)$ with respect to both $z$ and $\varepsilon$, but negatively related to the degrees of concavity, $\chi$ and $\theta$, of the utility functions in the first and second phases of the planning horizon, respectively. Higher degrees of concavity of the utility functions make students less responsive to educational and occupational opportunities under autarky and, as we shall see in the next section, to migration opportunities in an open economy. This is an important point as most of the literature on the impact of migration opportunities on skill formation in a developing country with an endogenous educational policy is based on the assumption that the utility function is either logarithmic or linear.

In sum, with endogenous study effort, the skill level of an agent depends positively on $\varepsilon$ through two channels: one direct and another indirect, through the interaction between the education policy of the authorities and the study effort, $z$, optimally chosen by each student. We thus have $H(\varepsilon, z(w, \varepsilon))$, with $d H / d \varepsilon=\partial H / \partial \varepsilon+(\partial H / \partial z)(\partial z / \partial \varepsilon)$, where the first term is the direct effect and the second term corresponds to the indirect "effort" effect, both being positive.

In a closed economy, the objective of the authorities is to maximize GNP, net of official expenditures on education. Each of the country's $N$ citizens is assumed to go through the educational system, receiving $\varepsilon$ units of training. From the perspective of the authorities, we take the per-student cost of providing an extra unit of training to be a constant $x$. Education is assumed to be funded by collecting taxes in a way that does not distort the decision of students with respect to the optimal study effort, $z$. An example might be collecting royalties on mining contracts or other resource-based activities.

In an autarky regime, signified by the superscript $a$, we can write the objective function of the authorities as 


$$
V^{a}=F(K, L)-N x \varepsilon
$$

where $F(K, L)$ is the aggregate production function with two inputs, capital $(K)$ and skilled labor $(L){ }^{5}$ The economy's stock of labor,

$$
L=N H(\varepsilon, z(w, \varepsilon))
$$

is measured in efficiency units. With perfect competition in the labor market and CRS technology of production, $w$ is the marginal productivity of an efficiency unit of labor as well as the real wage rate received by each worker per unit of skill. It depends only on $K / L$. Maximizing $V^{a}$ with respect to $\varepsilon$ requires that

$$
F_{L} \frac{d L}{d \varepsilon}=N x
$$

On the basis of eq. (7) and noting that the wage rate is endogenous, we have

$$
\frac{d L}{d \varepsilon}=\frac{N\left(H_{\varepsilon}+H_{z} \frac{\partial z}{\partial \varepsilon}\right)}{1-N H_{z} \frac{\partial z}{\partial w} \frac{\partial w}{\partial L}}>0
$$

Thus maximization of $V^{a}$ with respect to $\varepsilon$ implies that

$$
F_{L} \frac{\left(H_{\varepsilon}+H_{z} \frac{\partial z}{\partial \varepsilon}\right)}{1-N H_{z} \frac{\partial z}{\partial w} \frac{\partial w}{\partial L}}=x
$$

so that $x$, the marginal resource cost of an extra unit of training is equal to the marginal contribution of a unit of training, taking into account both its direct effect on skill formation and the indirect effect through its influence on students' effort stemming from both the change in $\varepsilon$ and in the market wage per unit of skill in general equilibrium.

\footnotetext{
${ }^{5}$ For notational simplicity, in eq. (6) we ignore income from resource-based activities, which is assumed to be constant.
} 


\subsection{International Capital Mobility and No Migration}

Consider next the step of opening our economy to international capital flows, while assuming that migration is still prohibited. More specifically, let us suppose that physical capital has become globally mobile, equalizing its rate of return across countries. It is natural to assume in such a scenario that $\mathrm{S}$ is a recipient of capital inflows. These inflows serve to lower its rate of return on capital to the global rate, $r^{*}$, and to raise the marginal productivity of skilled labor (and hence the real wage rate) to $\bar{w}$. As we shall see, this increase in the return to skills has not only a positive impact on the amount of effort exerted by students when accumulating human capital, but it also makes it optimal for the authorities of $\mathrm{S}$ to choose a larger $\varepsilon$.

Noting that with perfect international capital mobility the rates of return to capital and the real wage rate are pinned down at $r^{*}$ and $\bar{w}$, respectively, we can write the objective function of $\mathrm{S}$ as

$$
V^{k}=r^{*} K^{s}+\bar{w} N H(\varepsilon, z)-N x \varepsilon,
$$

where the superscript $k$ signifies that $\mathrm{S}$ is in a regime of perfect capital mobility and $K^{s}$ is the stock of capital owned by S. As indicated in (11), we continue to assume that the authorities seek to maximize national income (now distinct from GDP), net of educational expenditures. Maximization of $V^{k}$ with respect to $\varepsilon$ requires that

$$
\bar{w}\left(H_{\varepsilon}+H_{z} \frac{\partial z}{\partial \varepsilon}\right)=x .
$$

If we compare this condition with eq. (10), which is the optimality condition under autarky, we see that in the presence of capital mobility there are two new elements. First, the marginal productivity of labor is fixed at $\bar{w}$, which is greater than the marginal productivity of labor, $F_{L}$, under autarky. Second, the negative effect of an increase in 
$\varepsilon$ on $w$ (and hence on $z$ ) that we had to take into account under autarky, is no longer operational. Once we allow capital flows to stabilize the wage rate, $\frac{\partial w}{\partial L}=0$ and the expression $-N H_{z} \frac{\partial z}{\partial w} \frac{\partial w}{\partial L}$ in the denominator of eq. (10) does not appear in condition (12). For a given $x$, these two considerations imply that $\left(H_{\varepsilon}+H_{z} \frac{\partial z}{\partial \varepsilon}\right)$ must be smaller in the case of perfect capital mobility when compared with autarky. That is, a shift from an autarky regime to one of perfect international capital mobility makes it optimal for the authorities of $\mathrm{S}$ to provide more educational services (driving $H_{\varepsilon}$ lower) and for the students to exert more effort in accumulating human capital (driving $H_{z}$ lower as well). Benefits of opening $\mathrm{S}$ to capital mobility are therefore larger than they are in a setting with education policies exogenously given. Optimally adjusting the provision of educational services in response to capital inflows yields additional gains, with the gains being still larger if the optimal response of students is taken into account, as in the present model.

\subsection{International Migration Under a Quota}

Let us take the final step of opening S not only to perfect international capital mobility, but also to international migration to the advanced foreign country $\mathrm{F}$. We continue to assume that capital is globally mobile, keeping the rate of return on capital constant at $r^{*}$ throughout the world economy, including in our two countries of interest. The difference between $\mathrm{F}$ and $\mathrm{S}$ is assumed to be in terms of the technology of production and institutional structures that render the efficiency of productive inputs relatively higher in F. This implies a higher marginal productivity of labor in $\mathrm{F}$ when the rate of return on capital is $r^{*}$ in both countries.

Although migration from $\mathrm{S}$ to $\mathrm{F}$ is now possible, we shall assume that it is not unrestricted. F has an immigration quota that allows only $M$ workers to migrate from $\mathrm{S}$ and obtain permanent residence status. Since all workers in S are identical, they are all 
equally productive. We can then think of the migrants as being selected on the basis of a lottery and allocated to employers in F also on the basis of a lottery. Let us assume, in addition, that skills are not perfectly transferable from $\mathrm{S}$ to $\mathrm{F}$, so that a migrant with the skill level $H$ gets credit for only $\phi H$ units of skill in the labor market of $\mathrm{F}$, where $\phi \leq 1$. Moreover, the immigration policy of $\mathrm{F}$ is designed to benefit the country's employers. In some countries, including the rapidly-growing East-Asian economies, as well as in many of the labor-importing countries in the Middle East, the regulations allow foreign workers to be systematically underpaid in relation to native workers. ${ }^{6}$ In other economies, such as the U.S.A., the underpayment is more subtle, although it can be quite substantial. In the words of the former Secretary of Labor, Robert B. Reich, "We have seen numerous instances in which American businesses have brought in foreign skilled workers after having laid off skilled American workers, simply because they can get the foreign workers more cheaply" (Branigin, 1995). ${ }^{7}$ In what follows, we shall assume that while the natives earn $w^{*}$, foreign workers earn only $(1-\sigma) w^{*}$ per unit of transferable skills, where $\sigma<1$ is an exogenous parameter of the model.

\footnotetext{
${ }^{6}$ Migration programs in these countries are often negotiated at the bilateral level between the host and source counties, with compensation of foreign workers set to generate benefits for both the migrants and their employers.

${ }^{7}$ Under the H-1B program, US employers are required to pay foreign workers the "prevailing wages". These wages, however, have been defined too broadly, allowing employers to significantly undercut the salaries usually paid to Americans. Usher (2001) finds that "...some programmer analysts are being paid $\$ 30,000$ to $\$ 40,000$ less than prevailing salaries, about $\$ 100,000$, even though companies must sign documents stating they are paying H1-B visa holders the same salaries as their American counterparts." According to the Labor Department, the H-1B program has been widely exploited by employers to bring in thousands of foreign professionals and technicians "whose chief attraction is that they are willing to work for much lower salaries than their U.S. counterparts" (Branigin, 1995). As noted by Martin, Chen and Madamba (2000), "...many H-1B foreign workers want to find a United States employer to "sponsor" them for a permanent immigration EB visa; thus, as H-1B workers they are more willing to work long hours for lower pay than United States workers." Although the underpayment of any given foreign skilled worker is likely to be over just a limited period of time, it nonetheless generates a rent for the employer. To simplify our analysis, we do not model explicitly the wage-assimilation process of foreign workers. Instead, the employer's-rent component is simply assumed to be a fraction of a foreign worker's lifetime earnings. One can think of this fraction as being smaller, the lower the degree of dependency (under the regulations) of foreign workers in relation to their host-country employers and the greater the degree of mobility of foreign workers within the labor market of $\mathrm{F}$, all of which accelerates the pace at which their wages catch up with those of the natives.
} 
Within this framework, the expected period-two utility of consumption of a representative student in $\mathrm{S}$ at the beginning of the planning horizon is given by

$$
\begin{aligned}
E_{0}(u(C)) & =\frac{p}{1-\theta}\left[w^{*}(1-\sigma) \phi H\left(\varepsilon, z\left(\bar{w}, \varepsilon, p, w^{*}, \sigma, \phi\right)\right)\right]^{(1-\theta)}+ \\
& +\frac{1-p}{1-\theta}\left[\bar{w} H\left(\varepsilon, z\left(\bar{w}, \varepsilon, p, w^{*}, \sigma, \phi\right)\right)\right]^{1-\theta}
\end{aligned}
$$

where $p \equiv M / N$ is the probability that a skilled graduate in $\mathrm{S}$ will be able to migrate to $\mathrm{F}$ and earn $w^{*}(1-\sigma) \phi H\left(\varepsilon, z\left(\bar{w}, \varepsilon, M / N, w^{*}, \sigma, \phi\right)\right)$ instead of $\bar{w} H\left(\varepsilon, z\left(\bar{w}, \varepsilon, M / N, w^{*}, \sigma, \phi\right)\right)$, where we naturally assume that $w^{*}(1-\sigma) \phi>\bar{w}$. Note that once we allow for the possibility of working in $\mathrm{F}, z$ becomes a function of not only $\bar{w}$ and $\varepsilon$, as under autarky, but it also depends on the probability of ending up abroad, $M / N$, and on the conditions in the foreign labor market, as reflected in $w^{*}, \sigma$, and $\phi$.

\subsubsection{Optimal Educational Policy of the Source Country}

When $\mathrm{S}$ is open to emigration, let us assume that the aim of the authorities is to maximize the level of welfare of non-migrants. This is a reasonable assumption in the context of the present model as we do not consider explicitly any potential benefits that permanent migrants may provide to their country of origin after departure. They merely leave the remaining residents of $\mathrm{S}$ with the burden of having paid for everybody's subsidized education. We therefore assume that when $\mathrm{S}$ becomes open to international migration, the authorities choose $\varepsilon$ so as to maximize the country's GNP, net of educational expenditures, not taking into account the earnings or welfare of those who work abroad. ${ }^{8}$

$$
V=r^{*} K^{s}+\bar{w}(N-M) H\left(\varepsilon, z\left(\bar{w}, \varepsilon, M / N, w^{*}, \sigma, \phi\right)\right)-N x \varepsilon .
$$

\footnotetext{
${ }^{8}$ In making this assumption, we follow the mainstream of the literature on the brain drain. A notable exception is Bertoli and Brücker (2011), where the weight attached by the authorities of the source country to the utility of migrants is a parameter of the model.
} 
For a given $M$, the optimal education policy of $\mathrm{S}$ must satisfy the following condition.

$$
\frac{\partial V}{\partial \varepsilon}=V_{\varepsilon}=\bar{w}(N-M)\left(H_{\varepsilon}+H_{z} \frac{\partial z}{\partial \varepsilon}\right)-N x=0
$$

In comparing eq. (15) with (12), we immediately notice that $(N-M)<N$, which implies that the optimal provision of educational services must be such that $\left(H_{\varepsilon}+H_{z} \frac{\partial z}{\partial \varepsilon}\right)$ is larger when migration is permitted. This, however, does not necessarily call for a lower $\varepsilon$. As we shall see below, an increase in the educational efforts of students following the opening of the economy to emigration may, for a given $\varepsilon$, result in an increase in $\left(H_{\varepsilon}+H_{z} \frac{\partial z}{\partial \varepsilon}\right){ }^{9}$ This can more than offset the difference between $N-M$ and $N$, in which case a larger $\varepsilon$ is required to maximize the welfare of $\mathrm{S}$ when migration is permitted.

Using eqs. (4)-(5) along with the assumption that the marginal utility of leisure is constant (i.e., $\chi=0),{ }^{10}$ we can write $V_{\varepsilon}=\frac{\bar{w}(N-M) \beta H}{\varepsilon[1-\gamma(1-\theta)]}-N x$. Thus the second-order condition is satisfied as

$$
\frac{\partial V_{\varepsilon}}{\partial \varepsilon}=V_{\varepsilon \varepsilon}=\bar{w}(N-M)\left(H_{\varepsilon \varepsilon}+H_{z \varepsilon} \frac{\partial z}{\partial \varepsilon}+H_{z} \frac{\partial^{2} z}{\partial \varepsilon^{2}}\right)=\frac{\bar{w}(N-M) H \beta[\beta+\gamma(1-\theta)-1]}{\varepsilon^{2}[1-\gamma(1-\theta)]^{2}}<0 .
$$

\footnotetext{
${ }^{9} \mathrm{By}$ using (4) and (5), we can write $\partial\left(H_{\varepsilon}+H_{z} \frac{\partial z}{\partial \varepsilon}\right) / \partial z=\beta \gamma \mu z^{\gamma-1} \varepsilon^{\beta-1}+\frac{\beta \gamma \mu z^{\gamma-1} \varepsilon^{\beta}(1-\theta)}{\varepsilon[1-\gamma(1-\theta)]}+$ $\frac{\beta \gamma \mu(\gamma-1) z^{\gamma-1} \varepsilon^{\beta}(1-\theta)}{\varepsilon[1-\gamma(1-\theta)]}=\frac{\beta \gamma \mu z^{\gamma-1} \varepsilon^{\beta}}{\varepsilon[1-\gamma(1-\theta)]}>0$.

${ }^{10}$ This assumption makes the algebra more tractable in the analysis below. Note that the larger is $\chi$, the smaller is the effort response of students to incentives for human capital accumulation. This is because a larger $\chi$ makes it more difficult to give up leisure in exchange for future expected utility of consumption as the level of study effort increases. Thus, by assuming that $\chi=0$, the effect of a change in $\varepsilon$ or expected future earnings on $z$ (and therefore $H(\varepsilon, z)$ ) is larger than in the case where the marginal utility of leisure is diminishing. This stacks the cards in favor of the outcome that an increase in migration opportunities results in an increase in the net stock of human capital of the source country. In what follows, we shall assume that $\chi=0$, while noting where appropriate the implications of relaxing this assumption.
} 
Moreover,

$$
\begin{aligned}
\frac{\partial V_{\varepsilon}}{\partial M}=V_{\varepsilon M} & =\bar{w}\left[(N-M) \frac{\partial\left(H_{\varepsilon}+H_{z} \frac{\partial z}{\partial \varepsilon}\right)}{\partial M}-\left(H_{\varepsilon}+H_{z} \frac{\partial z}{\partial \varepsilon}\right)\right]= \\
& =\frac{\bar{w} \beta H}{\varepsilon[1-\gamma(1-\theta)]}\left[\frac{(N-M) \gamma \Delta}{M[1-\gamma(1-\theta)]}-1\right] \gtrless 0,
\end{aligned}
$$

where $\Delta<1$ is the the expected period-two gain in utility of a skilled worker stemming from being born in $\mathrm{S}$ when $\mathrm{S}$ is open rather than closed to international migration, divided by the expected period-two utility of a skilled worker when $\mathrm{S}$ is an open economy:

$$
\Delta \equiv \frac{\frac{M}{N}\left[\frac{\left[w^{*}(1-\sigma) \phi\right]^{1-\theta}}{(1-\theta)}-\frac{\bar{w}^{1-\theta}}{(1-\theta)}\right]}{\frac{M}{N} \frac{\left[w^{*}(1-\sigma) \phi\right]^{1-\theta}}{1-\theta}+\left(1-\frac{M}{N}\right) \frac{\bar{w}^{1-\theta}}{1-\theta}}<1 .
$$

In what follows, we shall refer to $\Delta$ as a skilled worker's "normalized" utility gain of being in an open economy rather than in one closed to international migration.

Thus, according to (17), in response to an increase in $M$ it may be optimal for the authorities of $\mathrm{S}$ to spend either more or less on education, depending on the parameters of the model. An increase in $\varepsilon$ is the optimal response if

$$
\Gamma \equiv \frac{(N-M) \gamma \Delta}{M[1-\gamma(1-\theta)]}>1
$$

Alternatively, if $\Gamma<1$, it is optimal for $\mathrm{S}$ to spend less on education following an increase in $M$.

The six schedules in Figure 1 illustrate combinations of the emigration rate $M / N$ and the international earnings differential, $w^{*}(1-\sigma) \phi / \bar{w}$, such that $\Gamma$ takes on the threshold value of unity. These schedules correspond to several combinations of $\theta$ and $\gamma(\theta=0.6$ and 0.7 and $\gamma=0.6,0.7$, and 0.8$)$, chosen merely to illustrate the relationship, with the source-country wage $\bar{w}$ normalized to 1 unit of output. For any emigration rate above (below) a given threshold schedule, $\Gamma$ is smaller (greater) than unity, implying that an 
increase in $M$ makes it optimal for $\mathrm{S}$ to reduce (raise) educational expenditures. As we shall see later, (19) is also the critical condition that determines if a larger $M$ chosen by the host country entails an increase or a decrease in the net stock of human capital (and welfare) in the source country when $\varepsilon$ is held constant. The net stock increases if $\Gamma>1$ and diminishes otherwise.

What Figure 1 shows very clearly is that the critical value of $M / N$ is positively related to the international earnings differential $w^{*}(1-\sigma) \phi / \bar{w}$ and the elasticity, $\gamma$, of the human-capital production function with respect to the amount of study effort expended by a student. Both a larger wage differential and a bigger $\gamma$ provide students with a stronger incentive to accumulate human capital in response to an increase in migration opportunities. On the other hand, the critical value of $M / N$ is inversely related to $\theta$, the degree of concavity of the utility function. A larger $\theta$ makes students' effort in school less sensitive to occupational opportunities later on in life. ${ }^{11}$

In sum, an increase in official spending on education in $\mathrm{S}$ is more likely to be the optimal response to an expansion of an immigration quota in F, (i) the smaller the skilled emigration rate, (ii) the greater the international earnings differential, $w^{*}(1-\sigma) \phi / \bar{w}$, (iii) the greater is $\gamma$, and (iv) the lower is $\theta$. An expansion of migration opportunities can then have a large impact on the effort of students in school, as well as a large impact on their subsequent productivity at the workplace. It then pays for the authorities of $\mathrm{S}$ to raise $\varepsilon$, considering the fact that when $M / N$ is small, the vast majority of students will end up in the labor market at home. We shall refer to an environment in which $\Gamma>1$ and hence $V_{\varepsilon M}>0$, as a "low-migration" (LM) equilibrium and the opposite case in which $\Gamma<1$ and $V_{\varepsilon M}<0$ as a "high-migration" (HM) equilibrium.

Proposition 1. If $\Gamma$ is greater (less) than unity, then the optimal expenditure on

\footnotetext{
${ }^{11}$ Similarly, if we were to allow for some concavity in the utility from leisure, $v(1-z)$, by assuming that $\chi>0$, this would reduce the threshold emigration rate for any given values of the remaining parameters of the model.
} 
education in $S$ increases (decreases) with an expansion of immigration opportunities in $F$.

Figure 1 also plots the data on the skilled emigration rates and international earnings differentials between the U.S.A. and a set of developing source countries covered by the study of Clemens, Montenegro and Pritchett (2009), CMP hereafter. The skilled emigration rates are for the year 2000 and come directly from Table A.1-2, column 3 of Docquier and Marfouk (2006). The data on wage differentials between the U.S.A. and each source country are for observably identical workers, as reported in column 6 , Table 1 of CMP.

If we take the position that the degree of concavity of the utility function is at least $\theta=0.7$ and that the elasticity of an individual's earnings with respect to effort in school is no greater than $\gamma=0.8$ (in which case a $1 \%$ increase in study effort in a given educational program results in a $0.8 \%$ increase in earnings), then only three of the 42 developing countries covered by the CMP study, namely Yemen (YA), Nigeria (NG), and Egypt (EG) are possible candidates for being classified as countries in an LM equilibrium. As noted in footnote 3 , a realistic value of $\theta$ is more likely to be around 0.9. Assuming that $\theta=0.9$, however, would generate threshold schedules in Figure 1 to the right of $w^{*}(1-\sigma) \phi / \bar{w}=20$, implying that none of the 42 countries in the CMP sample are in an LM equilibrium even for values of $\gamma>0.8$. Alternatively, if we take the relevant range of $\theta$ to include values as low as 0.6 , then Indonesia (ID), Venezuela (VE), India (IN), Jordan (JO), and Pakistan (PK) can also be added to Yemen (YA), Nigeria (NG), and Egypt (EG) on the list of LM countries. The remaining 34 economies covered by the CMP study may then be classified as being in an HM equilibrium, with some of them (Haiti, Sierra Leone, Ghana, Guyana, Jamaica, and Belize) not even appearing in Figure 1 because their emigration rates exceed 0.40 (see Table 1 for the complete list of countries and the data). 


\subsubsection{Optimal Immigration Policy of the Host Country}

Turning to the host country, admission of immigrants is for the purpose of enabling the employers to benefit from the opportunity to hire foreign labor. To capture the notion that migrants are expected to generate rents for their employers, we assume that the objective of $\mathrm{F}$ is to choose $\mathrm{M}$ that maximizes

$$
V^{*}=w^{*} \sigma \phi M H\left(\varepsilon, z\left(\bar{w}, \varepsilon, p, w^{*}, \sigma, \phi\right)\right)-Q(M)
$$

where the first term on the right represents total employers' rents generated by F's immigration policy and $Q(M)$ is the perceived cost for the society of hosting $M$ immigrants. In most of the host countries, the attitude of natives is negative when asked if more immigration is preferable. Facchini and Mayda (2008) find that in over twenty highand middle-income economies, less than 10 percent of respondents who gave an opinion about migration were in favor of increasing the number of immigrants to their country. Moreover, regions with a higher percentage of immigrants tend to have a higher probability of natives expressing negative attitudes to immigration. ${ }^{12}$ We shall assume in what follows that $Q^{\prime}(M)>0$ and $Q^{\prime \prime}(M)>0$.

Maximization of $V^{*}$ with respect to $M$ requires that

$$
\frac{\partial V^{*}}{\partial M}=V_{M}^{*}=R\left(1+\gamma \eta_{z M}\right)-Q^{\prime}(M)=0,
$$

where $R=w^{*} \sigma \phi H\left(\varepsilon, z\left(\bar{w}, \varepsilon, M / N, w^{*}, \sigma, \phi\right)\right)$ is the per-worker rent enjoyed by the employers of skilled immigrants, $\gamma$ is the elasticities of $\mathrm{H}(.,$.$) with respect to z$ (see eq. (5)) and $\eta_{z M}$ is the elasticity of $z$ with respect to $M$ :

$$
\eta_{z M}=\frac{\Delta}{1-\gamma(1-\theta)}>0 .
$$

\footnotetext{
${ }^{12}$ See, for example, Schlueter and Wagner (2008) and Markaki and Longhi (2012).
} 
An expansion of the immigration quota stimulates students' effort in $\mathrm{S}$ by increasing the probability of being able to migrate. The optimal immigration policy implied by eq. (21) therefore requires admission of skilled workers beyond the point where the rent, $R$, generated per migrant is equal to the marginal cost, $Q^{\prime}(M)$, of admitting an extra worker. This is because a more generous admissions policy implies a higher level of skill in possession of each immigrant and hence larger rents enjoyed by F's employers on the entire stock of foreign labor employed in the economy. In terms of the parameters of the model, a lower degree of concavity of the utility function $(\theta)$, a higher elasticity of $H(.,$.$) with respect to a student's effort in school (\gamma)$ and, recalling the definition of $\Delta$, a larger international wage differential, all work in the same direction to provide $\mathrm{F}$ with a stronger incentive to admit immigrants beyond the point where $R=Q^{\prime}(M)$.

If the degree of convexity of $Q(M)$ is sufficiently high, which we assume to be the case ${ }^{13}$ the second-order condition for the maximization of $V^{*}$ is satisfied.

$$
\frac{\partial V_{M}^{*}}{\partial M}=V_{M M}^{*}=\frac{R \gamma \Delta}{[1-\gamma(1-\theta)] M}\left[1+\gamma \eta_{z M}+(1-\Delta)\right]-Q^{\prime \prime}(M)<0 .
$$

Also note that

$$
\frac{\partial V_{M}^{*}}{\partial \varepsilon}=V_{M \varepsilon}^{*}=\frac{R \beta}{\varepsilon[1-\gamma(1-\theta)]}\left(1+\gamma \eta_{z M}\right)>0
$$

which states that the higher the provision of educational services in $\mathrm{S}$, the stronger the incentive for $\mathrm{F}$ to admit more immigrants. This completes the presentation of our model's structure.

\footnotetext{
${ }^{13}$ The degree of convexity of the $Q(M)$ function must be such that $\frac{Q^{\prime \prime}(M) M}{Q^{\prime}(M)}>\left[1+\frac{(1-\Delta)}{1+\gamma \eta_{z} M}\right]\left[\frac{\gamma \Delta}{[1-\gamma(1-\theta)]}\right]$. If we consider, for example, the case in which $\gamma=0.8, \theta=0.6, M / N=0.05$, and the international earnings differential, $w^{*}(1-\sigma) \phi / \bar{w}=4$, with $\bar{w}$ normalized to unity, a value of $\frac{Q^{\prime \prime}(M) M}{Q^{\prime}(M)}>0.079$ is required to satisfy the second order condition. It can be shown that this critical value is decreasing in $\theta$ and increasing in $\gamma$, $M / N$, and the international earnings differential.
} 


\section{Nash Equilibrium}

We consider the case of both countries simultaneously choosing their policies in a noncooperative manner so as to maximize their individual welfare. For the source country, the optimal level of spending on education $(\varepsilon)$ is implicitly given by eq. (15), which is its reaction function, $V_{\varepsilon}=0$, while the host country sets its optimal immigration quota $(M)$ on the basis of its own reaction function, $V_{M}^{*}=0$, as given by eq. (21). The slope of $V_{\varepsilon}=0$ is

$$
\left.\frac{d \varepsilon}{d M}\right|_{V_{\varepsilon}=0}=-\frac{V_{\varepsilon M}}{V_{\varepsilon \varepsilon}}=\frac{\varepsilon[1-\gamma(1-\theta)](\Gamma-1)}{(N-M)[1-\beta-\gamma(1-\theta)]} \gtrless 0 .
$$

Noting that $\beta+\gamma(1-\theta)<1$ in the denominator, the slope of $V_{\varepsilon}$ is positive for parameter values corresponding to an LM equilibrium (i.e., $\Gamma>1$ ) and negative in an HM equilibrium (i.e., $\Gamma<1$ ).

The slope of F's reaction function is unambiguously positive.

$$
\left.\frac{d \varepsilon}{d M}\right|_{V_{M}^{*}=0}=-\frac{V_{M M}^{*}}{V_{M \varepsilon}^{*}}=\frac{\gamma \varepsilon \Delta\left(1+\gamma \eta_{z M}+1-\Delta\right)-Q^{\prime \prime}(M)}{M \beta\left(1+\gamma \eta_{z M}\right)}>0,
$$

as $V_{M M}^{*}<0$ and $V_{M \varepsilon}^{*}>0$. Note that $1-\Delta$ is a positive fraction representing the ratio of the period-two utility of working at home for the real wage $\bar{w}$, to the expected period-two utility when the probability of migration is $M / N$.

\subsection{Comparative statics}

Let us examines the implications of changes in the key exogenous variables on the Nash equilibrium values of the policy instruments of the two countries. By totally differenti- 
ating the reaction functions (15) and (21), we obtain

$\left[\begin{array}{cc}V_{\varepsilon \varepsilon} & V_{\varepsilon M} \\ V_{M \varepsilon}^{*} & V_{M M}^{*}\end{array}\right]\left[\begin{array}{c}d \varepsilon \\ d M\end{array}\right]=\left[\begin{array}{c}-V_{\varepsilon x} \\ 0\end{array}\right] d x+\left[\begin{array}{c}-V_{\varepsilon \phi} \\ -V_{M \phi}^{*}\end{array}\right] d \phi+\left[\begin{array}{c}0 \\ -V_{M Q^{\prime}(M)}^{*}\end{array}\right] d Q^{\prime}(M)$,

where $V_{\varepsilon x}=-N, V_{\varepsilon \phi}=(N-M) \bar{w} \beta \gamma H\left[\Delta+\frac{M}{N}(1-\Delta)\right] / \varepsilon \phi[1-\gamma(1-\theta)]^{2}>0, V_{M \phi}^{*}=$ $R\left\{\gamma(1-\theta)\left[(1-\Delta)\left(\Delta+\frac{M}{N}(1-\Delta)\right)\right]+\left(1+\gamma \eta_{z M}\right)[1-\gamma(1-\theta)+\gamma(1-\theta)[(1-\Delta)(\Delta+\right.$ $\left.\left.\left.\left.\frac{M}{N}(1-\Delta)\right)\right]\right]\right\} / \phi[1-\gamma(1-\theta)]>0$, and $V_{M Q^{\prime}(M)}^{*}=-1$.

The system (27) enables us to solve for the impact of changes in the exogenous variables, including $x, \phi$, and the perceived marginal cost of admitting immigrants into F, $Q^{\prime}(M)$, on the equilibrium values of $M$ and $\varepsilon$. Stability of the Nash equilibrium requires that the determinant $\Omega=V_{\varepsilon \varepsilon} V_{M M}^{*}-V_{M \varepsilon}^{*} V_{\varepsilon M}>0$. This implies that in an LM equilibrium, depicted in Figure 2(b), the positively sloped $V_{M}^{*}=0$ schedule must be steeper than the $V_{\varepsilon}=0$ schedule. In an HM equilibrium, depicted in Figure 2(a), the $V_{\varepsilon}=0$ schedule is negatively sloped.

\subsection{Change in the cost of providing education}

It is interesting in the present context to examine the implications of technological innovations that lower the cost of educating students. Recent improvements in communications and information technologies have lowered the cost of transmitting information through the educational system, giving both teachers and students much quicker, more efficient, and lower-cost access to knowledge and educational tools. We can think of these new technologies as being instrumental in lowering the cost, $x$, that the authorities face in providing a unit of educational services to students in S.

Using the system of eqs. (27) the effects of a decline in $x$ on the Nash-equilibrium values of $\varepsilon$ and $M$ are as follows. 


$$
\begin{aligned}
& \Omega \frac{d \varepsilon}{d x}=-V_{M M}^{*} V_{\varepsilon x}=N V_{M M}^{*}<0 \\
& \Omega \frac{d M}{d x}=V_{M \varepsilon}^{*} V_{\varepsilon x}=-N V_{M \varepsilon}^{*}<0 .
\end{aligned}
$$

The best response of $S$ to a decline in the cost of education is to provide more $\varepsilon$ to its students. With the now higher level of education in $S$ and a correspondingly greater effort on the part of students to acquire skills, the best response of $F$ is to admit more immigrants. In Figures 2(a) and 2(b) a reduction in $x$ gives rise to an upward shift of the reaction function of S from $\left(V_{\varepsilon}=0\right)$ to $\left(V_{\varepsilon}=0\right)^{\prime}$, while leaving the $V_{M}^{*}=0$ schedule unaffected. The Nash equilibrium therefore moves from point A to point B. In both panels this entails an increase in the equilibrium levels of $\varepsilon$ and $\mathrm{M}$, but more so in an LM equilibrium of Figure 2(b), as the vertical shift of the $V_{\varepsilon}=0$ schedule is of the same magnitude in both panels (i.e., $\left.V_{\varepsilon x}=-N\right)$.

Improvements in education technology can therefore be expected to have a positive impact on the provision of educational services in $\mathrm{S}$ and on the level of skills possessed by its graduates. This effect is reinforced by the endogenous immigration-policy response of F in an LM equilibrium of Figure 2(b) and mitigated in an HM equilibrium of Figure 2(a). Since the conditions in the relatively poorer developing countries, with low wages, are more likely to meet the criteria for a "low-migration" equilibrium (when compared with the conditions in the relatively more prosperous developing economies, other things being equal), our model suggests that technological improvements in the education industry can help contribute to a pattern of skill-level convergence among graduates across the developing world. This follows from the model's implication that for a country in an LM equilibrium, the interaction between education and immigration policies of $\mathrm{S}$ and $\mathrm{F}$ helps to stimulate educational spending and study effort of students, while for one in an HM equilibrium it has a negative impact on $\varepsilon$ and $z$. 


\subsection{Drop in the marginal cost of hosting immigrants}

Suppose that the population of F undergoes an exogenous shift in it's attitude towards immigration. To be more concrete, let us assume that the perceived cost of hosting immigrants is given by $Q(M)=q_{0}+q_{1} M^{2}$, where $q_{0}$ and $q_{1}$ are positive, exogenously given parameters and $Q^{\prime}(M)=2 q_{1} M$. A change in the perceived marginal cost of hosting immigrants in that case corresponds to a change in $q_{1}$.

On the basis of eqs. (27) we can solve for the effects of a change in $Q^{\prime}(M)$ on $\varepsilon$ and $M$. Noting that $V_{M Q^{\prime}(M)}^{*}=-1$, we have

$$
\begin{gathered}
\Omega \frac{d \varepsilon}{d Q^{\prime}(M)}=-V_{\varepsilon M} \gtrless 0 \text {, as } \Gamma \lessgtr 1, \\
\Omega \frac{d M}{d Q^{\prime}(M)}=V_{\varepsilon \varepsilon}<0 .
\end{gathered}
$$

Eq. (31) shows that when the perceived marginal cost of hosting immigrants decreases, the Nash equilibrium level of F's immigration quota increases. The effect on the provision of educational services in $\mathrm{S}$ is ambiguous, however, as indicated in eq. (30). In an HM scenario, with a negatively sloped $V_{\varepsilon}=0$ schedule, the source country's best response to an expansion of the immigration quota in $\mathrm{F}$ is to lower $\varepsilon$. This can be seen in Figure 2(a), where starting from an initial $\mathrm{HM}$ equilibrium at point $\mathrm{A}$, a reduction in $Q^{\prime}(M)$ shifts the $\left(V_{M}^{*}=0\right)$ schedule to the right so that the new $\left(V_{M}^{*}=0\right)^{\prime}$ schedule intersects the unaffected $V_{\varepsilon}=0$ locus at point C. This results in a higher Nash-equilibrium value of $M$ and a lower $\varepsilon$. Alternatively, in an LM equilibrium, an increase in $M$ raises the level of education provided in S. This is illustrated in Figure 2(b), where the Nash equilibrium moves from point $\mathrm{A}$ to $\mathrm{C}$ in response to a rightward shift of the $V_{M}^{*}=0$ locus. 


\subsection{Change in $\phi$}

The productivity of a potential migrant in any given environment depends on her training. In Sub-Saharan Africa, where the medical brain drain is an alarming phenomenon in the countries experiencing severe shortages of health workers, there are calls for adjustments in the education curricula of doctors and nurses so as to make them better trained to address local health problems and less attractive to recruiting agencies trying to fill vacancies at health institutions in the advanced countries. ${ }^{14}$

Let us assume in what follows that the education curricula in $\mathrm{S}$ is reformed such that any given stock of human capital accumulated by students is less productive in F, while leaving the function $H(\varepsilon, z)$ unaffected. In terms of our model this can be captured by an exogenous decline in $\phi$. Using the system of eqs. (27), we obtain the following effects of a reduction in $\phi$ on the Nash equilibrium values of $\varepsilon$ and $M$ :

$$
\begin{aligned}
& \Omega \frac{d \varepsilon}{d \phi}=V_{M \phi}^{*} V_{\varepsilon M}-V_{M M}^{*} V_{\varepsilon \phi} \gtrless 0, \\
& \Omega \frac{d M}{d \phi}=V_{\varepsilon \phi} V_{M \varepsilon}^{*}-V_{M \phi}^{*} V_{\varepsilon \varepsilon}>0,
\end{aligned}
$$

where we recall that $V_{M \phi}^{*}>0, V_{\varepsilon \phi}>0, V_{M \varepsilon}^{*}>0, V_{M M}^{*}<0, V_{\varepsilon \varepsilon}<0$, and the sign of $V_{\varepsilon M}$ is the same as that of $\Gamma-1$. The effect of a reduction in $\phi$ on the Nash-equilibrium level of spending on education is ambiguous and depends on the slope of the reaction function of S. In relation to the problem of the medical brain drain, the empirically relevant case

\footnotetext{
${ }^{14}$ Focus Migration (2007) notes that there is an "urgent need for countries to examine medical education curricula to ensure that training programmes focus on domestic, rather than foreign, healthcare problems." Similarly, Physicians for Human Rights (2004) recommends that "African health training institutions should adjust their curricula to prepare graduates for the conditions in which most will practice in Africa, including an emphasis on primary health care and common health problems" (Physicians for Human Rights, 2004, p.6). The World Health Organization (2002) proposes a "relevance test," whereby health science and medical curricula in Africa should be tested to ensure that at least $80 \%$ of the curriculum content covers the conditions that are major determinants of health and well being in the respective country.
} 
is that of an HM equilibrium with a negatively sloped $V_{\varepsilon}=0$ locus. This is illustrated in Figure 3(a), where a reduction in $\phi$ shifts the $V_{\varepsilon}=0$ schedule down and to the left and the $V_{M}^{*}=0$ schedule up and to the left. In relation to the original equilibrium at $\mathrm{A}$, we find that the immigration quota of $\mathrm{F}$ is unambiguously lower. Depending on the relative magnitudes of the two shifts, however, the new equilibrium can feature either a higher or a lower $\varepsilon$. The leftward shift of the $V_{M}^{*}=0$ schedule is greater than that of the $V_{\varepsilon}=0$ locus if $-V_{M \phi}^{*} / V_{M M}^{*}>-V_{\varepsilon \phi} / V_{\varepsilon M}$. The Nash-equilibrium then moves to D", where the level of $\varepsilon$ is higher. This would be the case, for instance, if the size of the immigration quota of $\mathrm{F}$ is highly sensitive to the amount of (marketable) human capital in possession of potential immigrants, which makes $V_{M \phi}^{*}$ relatively large. Alternatively, if the sensitivity of F's quota to the stock of human capital that immigrants bring into the economy is sufficiently low, the leftward shift of the $V_{M}^{*}=0$ schedule is smaller than that of $V_{\varepsilon}=0$. The new equilibrium is then at D', where it is optimal for $\mathrm{S}$ to lower $\varepsilon$ when it restructures its training program with the aim of reducing $\phi$.

If we consider an equilibrium characterized as LM, it makes more sense for $\mathrm{S}$ to revise its education curricula so as to increase the market value of the skills possessed by its citizens working abroad. The implications of such an increase in $\phi$ in an LM equilibrium are illustrated in Figure 3(b) by a shift of the Nash equilibrium from point A to D. Curriculum reform then unambiguously makes more spending on education optimal in S and more immigration optimal for F. A higher $\varepsilon$ and a higher $M$, as well as the increase in $\phi$ stemming from the curriculum change, provide students in S with stronger incentives to study, contributing to a more skilled and more productive labor force both at home and abroad.

\section{Proposition 2.}

- A decline in the cost of education in $S$, increases the Nash equilibrium levels of both educational spending and immigration quota. 
- A decrease in the marginal cost of hosting immigrants in F, increases the Nashequilibrium level of the immigration quota and increases (decreases) educational spending in a low- (high-) migration equilibrium.

- In a high-migration equilibrium a decrease in the international transferability of skills from $S$ to $F$ lowers the Nash-equilibrium level of the immigration quota and has an ambiguous effect on educational spending.

- In a low-migration equilibrium an increase in the transferability of skills from $S$ to $F$ has a positive effect on the level of spending on education as well as on the immigration quota.

\section{Conclusions}

Instead of repeating the principal findings of this study, which are conveniently summarized in the form of Propositions 1 and 2, we conclude the paper by discussing its main contributions at a more general level. There are two key elements and both of them flow directly from the model's structure. To begin with, this is the first contribution to the literature on the brain drain that examines the interaction between a host-country's immigration policy and a source-country's education policy when both are endogenous and where students optimally choose how much effort to apply in the process of human capital accumulation. This structure enables us to investigate the impact of exogenous shocks, such as a technological improvement that lowers the cost of providing educational services in the source country, a shift in preferences on immigration in the host country, and a change in the degree of international transferability of human capital, on the amount of effort expended by students in school, the optimal level of source-country spending on education, and the optimal immigration quota of the host country.

The second key contribution relates to the way we model skill formation. Instead 
of having to purchase human capital (with or without access to credit), as is typically assumed in the earlier contributions to the literature on education policies and the brain drain, we assume that students in the source country have free access to public education, while the authorities choose the optimal provision of training. Students then maximize their utility from consumption and leisure by choosing the optimal amount of effort they apply in the process of human-capital accumulation. Within this framework, the concavity of the utility function plays a decisive role in terms of how students respond to educational and occupational opportunities at home and abroad. If the elasticity of marginal utility of consumption, $\theta$, exceeds unity, greater opportunities that can be expected to generate a higher level of future income, induce students to exert less effort in acquiring human capital (i.e., the income effect dominates the substitution effect). In this case there is no scope for any source-country benefits in our model as a result of greater prospects of being able to migrate as a skilled worker.

Expansion of migration opportunities does increase the source-country's gross stock of human capital in the empirically relevant case of $\theta<1$. Whether or not it increases the net stock, depends on the elasticity, $\gamma$, of the human capital production function with respect to a student's effort, the international wage differential, the elasticity of marginal utility of consumption, $\theta$, as well as the emigration rate, $M / N$, in the initial equilibrium. Our model implies that there is scope for a net brain gain only in a "low-migration" equilibrium, characterized by a large $\gamma$, a low $\theta$, a low $M / N$, and a sufficiently large gap between earnings of a skilled worker at home and abroad. In examining the required combinations of parameters such that the source country can be characterized as being in a "low-migration" equilibrium, we find on the basis of evidence on skilled emigration rates and wage differentials provided by Docquier and Marfouk (2006) and Clemens, Montenegro and Pritchett (2009), respectively, that a net brain gain is unlikely to be a common phenomenon. This conclusion is largely supported by the empirical findings 
of Beine, Docquier and Rapoport (2008), which suggest that only a handful of counties with low emigration rates and low levels of human capital are likely to enjoy a migrationinduced net increase in their stock of skilled labor in excess of $1 \%$. The implications of our theoretical model are also consistent with the findings of Docquier, Faye, and Pestieau (2008), which indicate that taking into account the endogeneity of education policies of source countries, it is less likely that greater migration opportunities will result in a net increase in the stock of human capital throughout the developing world. Our model, with a micro foundation that might be more fitting in the case of very poor developing countries, projects an even more pessimistic view regarding the prospects of a brain gain. 


\section{References}

[1] Beine, M., F. Docquier, and C. Oden-Defoort, 2011, "A Panel Data Analysis of the Brain Gain," World Development, vol. 39 (4): 523-32.

[2] Beine, M., F. Docquier, and H. Rapoport, 2001, "Brain Drain and Economic Growth: Theory and Evidence," Journal of Development Economics, vol. 64: 275-289.

[3] Beine, M., F. Docquier, and H. Rapoport, 2007, "Measuring International Skilled Migration: A New Database Controlling for Age of Entry," World Bank Economic Review, vol. 21 (2): 249-254.

[4] Beine, M., F. Docquier, and H. Rapoport, 2008, "Brain Drain and Human Capital Formation in Developing Countries: Winners and Losers," Economic Journal, vol. 118: $631-652$.

[5] Beine, M., F. Docquier, and H. Rapoport, 2010, "On the Robustness of Brain Gain Estimates," Annals d'Economie and de Statistique, vol. 97-98: 143-65.

[6] Belot, M.V.K. and T.J. Hatton, 2012, "Immigrant Selection in the OECD," Scandinavian Journal of Economics vol. 114(4): 1105-1128.

[7] Bertoli, S., Brücker, H., 2011, "Selective Immigration Policies, Migrants' Education and Welfare at Origin," Economics Letters vol. 113: 19-22.

[8] Bhagwati, J.N., and K. Hamada, 1974, "The Brain Drain, International Integration of Markets for Professionals and Unemployment," Journal of Development Economics, vol. 1: 19-42.

[9] Blundell, R., A. Duncan, and C. Meghir, 1998, "Estimating Labor Supply Responses Using Tax Reforms," Econometrica, vol. 66: 827-862.

[10] Branigin, W., 1995, "White-Collar Visas: Back Door for Cheap Labor?" Washington Post, Saturday, October 21, 1995, Page A1. 
[11] Carrington, W.J., and E. Detragiache, 1998, "How Big is the Brain Drain," IMF Working Paper 201.

[12] Chand, S., and M. A. Clemens., 2008, "Skilled Emigration and Skill Creation: A Quasi-experiment," Center for Global Development Working Paper 152.

[13] Clemens, M.A., C.E. Montenegro, and L. Pritchett, "The Place Premium: Wage Differences for Identical Workers Across US Border," RWP09-004, Harvard Kennedy School, 2009.

[14] Chetty, R., 2006, "A New Method of Estimating Risk Aversion," American Economic Review, vol. 96: 1821-1834.

[15] Djajić, S., 1989, "Skills and the Pattern of Migration: The Role of Qualitative and Quantitative Restrictions on International Labor Mobility," International Economic Review, vol. 40: 795-809.

[16] Djajić, S., M.S. Michael, and A. Vinogradova, 2012, "Migration of Skilled Workers: Policy Interaction between Host and Source Countries," Journal of Public Economics, vol. 96: 1015-1024.

[17] Docquier, F., O. Faye, and P. Pestieau, 2008, "Is Migration a Good Substitute for Education Subsidies?" Journal of Development Economics, vol. 86: 263-276.

[18] Docquier, F., and A. Marfouk, 2006, International Migration by Educational Attainment (1990-2000)," in C. Ozden and M. Schiff, eds., International Migration, Remittances and the Brain Drain (Palgrave-Macmillan).

[19] Docquier, F., and H. Rapoport, 2008, "Skilled Migration: The Perspective of Developing Countries," World Bank Policy Research Paper No. 3382.

[20] Docquier, F., and H. Rapoport, 2012, "Globalization, Brain Drain and Development," Journal of Economic Literature, vol. 50: 681-730. 
[21] Domingues Dos Santos, M., and F. Postel-Vinay, 2003, "Migration as a Source of Growth: The Prospects of a Developing Country," Journal of Population Economics, vol. 16: 161-175.

[22] Easterly, W. and Y. Nyarko, 2009, "Is the Brain Drain Good for Africa?" In Skilled Immigration Today: Prospects, Problems, and Policies, edited by Jagdish Bhagwati and Gordon Hanson, Oxford and New York: Oxford University Press.

[23] Facchini, G., and A.-M. Mayda, 2008, "From Individual Attitudes Towards Migrants to Migration Policy Outcomes: Theory and Evidence," Economic Policy, vol. 56: 651-713.

[24] Focus Migration, 2007, "Migration and Recruitment of Healthcare Professionals: Causes, Consequences and Policy Responses," Policy Brief no.7, Hamburg Institute of International Economics (HWWI).

[25] Gibson, J., and D. McKenzie, 2011, "The Microeconomic Determinants of Emigration and Return Migration of the Best and Brightest: Evidence from the Pacific," Journal of Development Economics, vol. 95 (1): 18-29.

[26] Grogger J., and G.H. Hanson, 2011, "Income Maximization and the Selection and Sorting of International Migrants," Journal of Development Economics 95: 42-57.

[27] Justman, M., and J. Thisse, 1997, "Implications of the Mobility of Skilled Labor for Local Public Funding of Higher Education," Economics Letters, vol. 55: 409-412.

[28] Lucas, R.E.B., 2005, International Migration Regimes and Economic Development, Edward Elgar Publishing, Northampton, Massachusetts, USA.

[29] Markaki, Y. and S. Longhi, 2012, "What Determines Attitudes to Immigration in European Countries? An Analysis at the Regional Level," Norface Migration Discussion Paper No. 2012-32. 
[30] Martin, P., R. Chen, and M. Madamba, 2001, "United States Policies for Admission of Professional and Technical Workers: Objectives and Outcomes," International Migration Papers, No. 35, ILO, Geneva.

[31] Miyagiwa, K., 1991, "Scale Economies in Education and the Brain Drain Problem," International Economic Review, vol. 32 (3): 743-59.

[32] Mountford, A., 1997, "Can a Brain Drain be Good for Growth in the Source Economy?" Journal of Development Economics, vol. 53: 287-303.

[33] Physicians for Human Rights, 2004, "An Action Plan to Prevent Brain Drain: Building Equitable Health Systems in Africa," report prepared by Physicians for Human Rights, Boston, MA.

[34] Schlueter, E. and U. Wagner, (2008) "Regional Differences Matter: Examining the Dual Influence of the Regional Size of the Immigrant Population on Derogation of Immigrants in Europe," International Journal of Comparative Sociology, vol. 49(23): 153-173.

[35] Stark, O., C. Helmenstein, and A. Prskawetz, 1997, "A Brain Gain with a Brain Drain," Economics Letters, vol. 55: 227-234.

[36] Stark, O. and Y. Wang, 2002, "Inducing Human Capital Formation: Migration as a Substitute for Subsidies," Journal of Public Economics, vol. 86: 29-46.

[37] Vidal, J.-P., 1998, " The Effect of Emigration on Human Capital Formation," Journal of Population Economics, vol. 11: 589-600.

[38] Usher, A., 2001, "You're Fired, Go Home," Washington Post, May 10, 2001.

[39] World Health Organization, 2002, "Placing Health Workers at the Heart of Health Services Delivery in Africa: The People who Work for Our Health," WHO, Regional Office for Africa. 
[40] Wong, K.-y., 1997, "Endogenous Growth and International Migration," in B. Jensen and K.-y. Wong eds., Dynamics, Growth and International Trade (Ann Arbor: U. of Michigan Press).

[41] Wong, K.-y., and C.K. Yip, 1999, "Education, Economic Growth and Brain Drain," Journal of Economic Dynamics and Control, vol. 23: 699-726. 


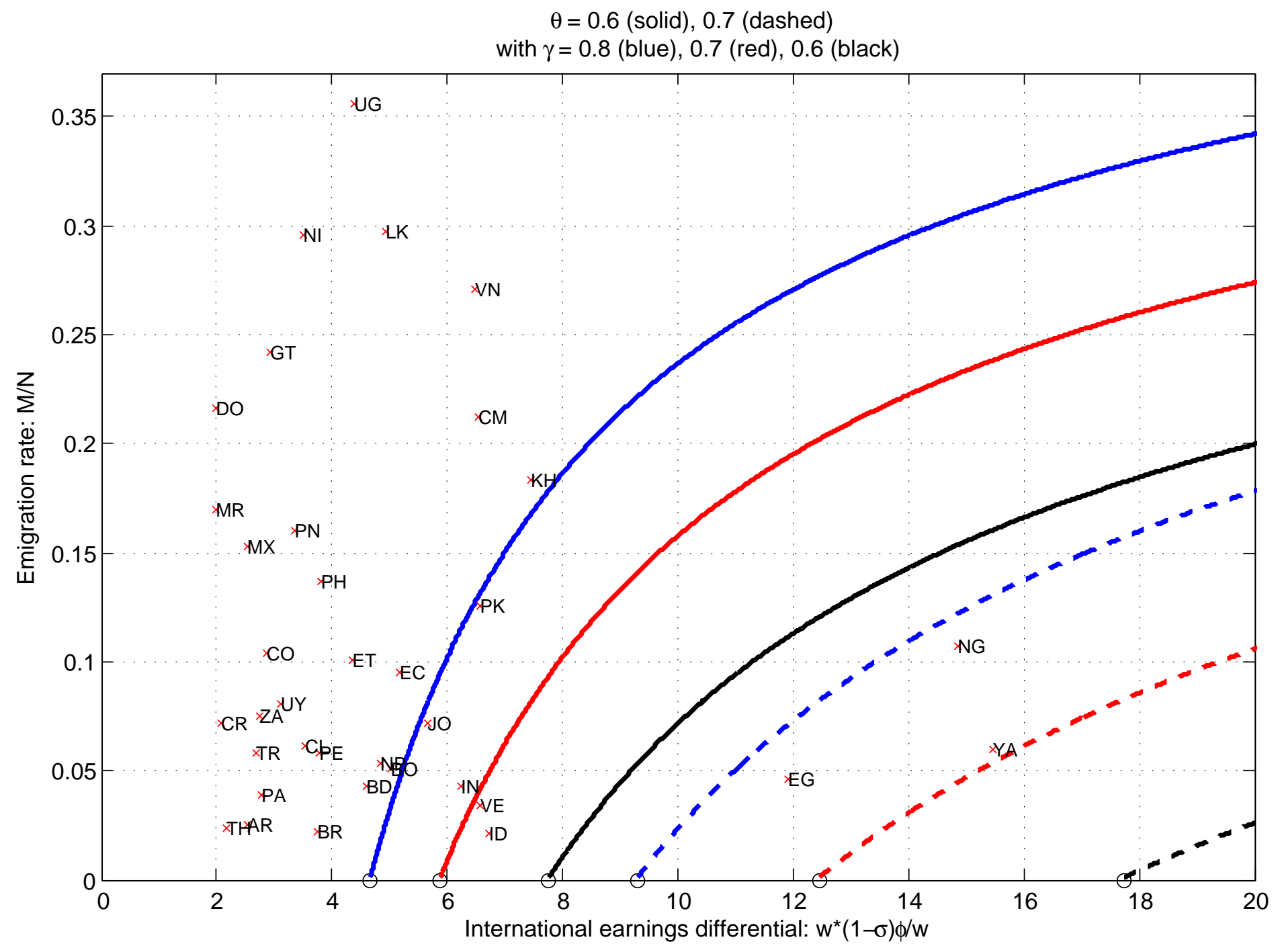

Figure 1: Threshold schedules 


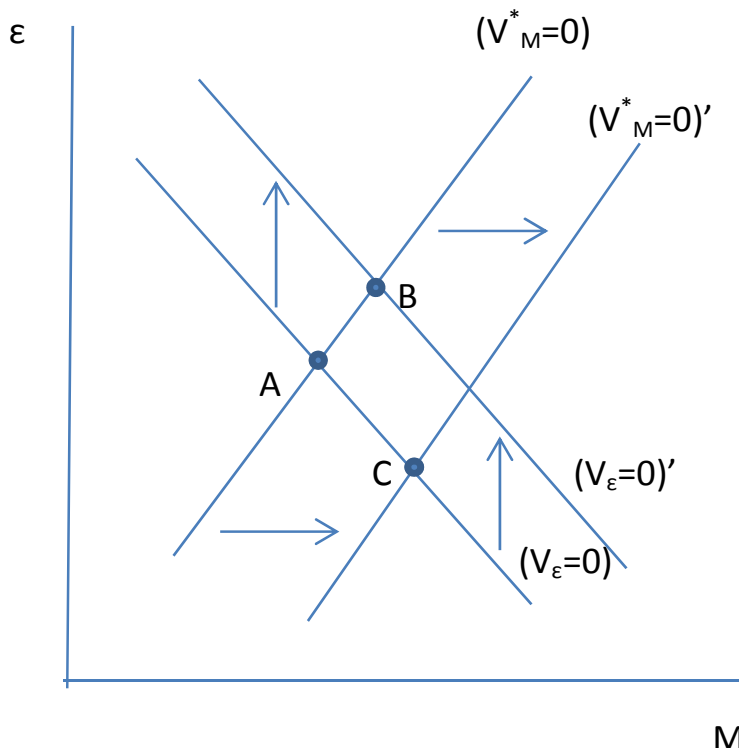

Fig. 2(a)

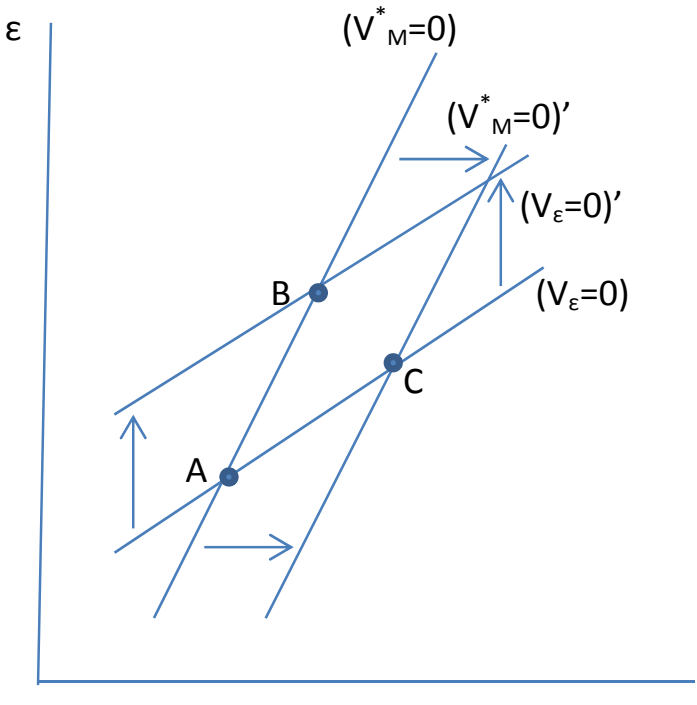

M

Fig. 2(b)

Fig. 2(a) shows the case where $\mathrm{V}_{\varepsilon \mathrm{M}}<0$ and the slope of the reaction function for $\mathrm{S}$ is negative. Fig. 2(b) shows the case where $V_{\varepsilon M}>0$ and the slope of the reaction function for $S$ is positive. In both cases i) a decrease in the cost of education moves the Nash equilibrium from point A to point $B$ and ii) a decrease in the perceived marginal cost of hosting immigrants moves the Nash equilibrium from point $A$ to point $C$. 


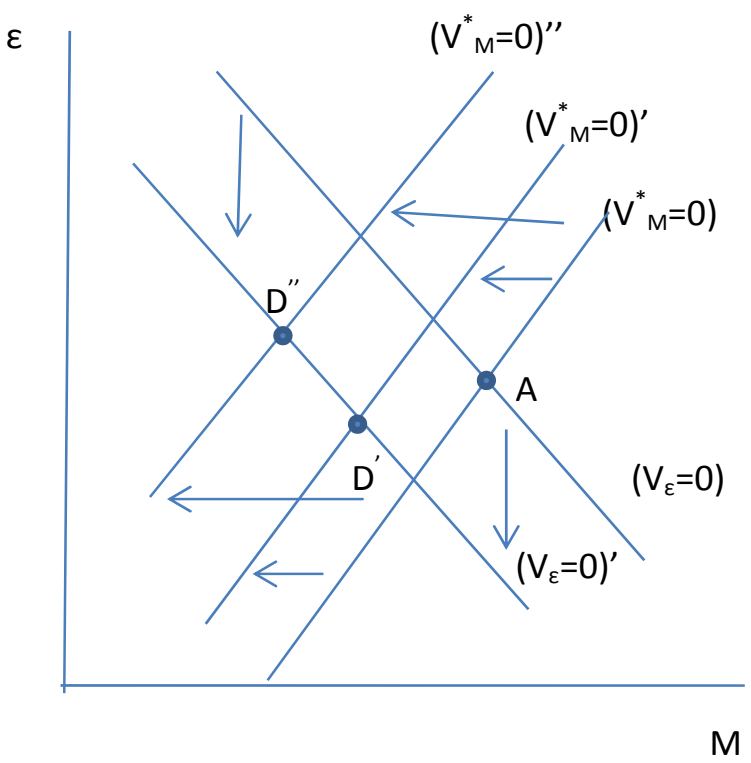

Fig. 3(a)

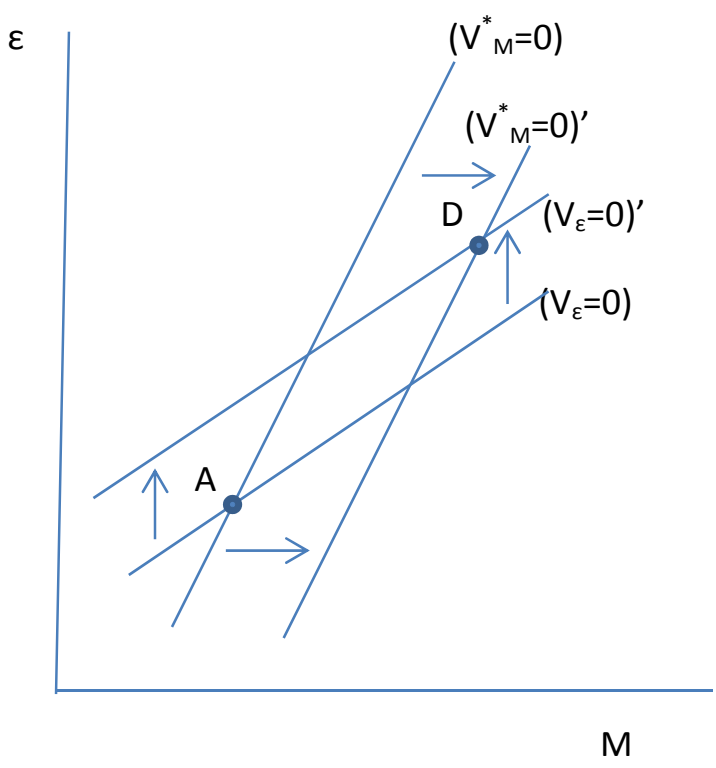

Fig. 3(b)

Fig. 3(a) shows the case where $V_{\varepsilon M}<0$ and the slope of the reaction function for $S$ is negative. $A$ decrease in $\phi$ moves the Nash equilibrium from point A to points such as $D^{\prime}$ or $D^{\prime \prime}$, depending on the relative magnitudes of the leftward shifts of the $V_{M}{ }_{M}=0$ and the $V_{\varepsilon}=0$ schedules. Fig. 3(b) shows the case where $V_{\varepsilon M}>0$ and the slope of the reaction function for $S$ is positive. An increase in $\phi$ moves the Nash equilibrium from point $A$ to point $D$. 
Table 1. Emigration rates and wage differentials between the U.S.A. and the 42 developing countries covered by Clemens, Montenegro and Pritchett (2009).

\begin{tabular}{|c|c|c|c|}
\hline Country & Country code & $\begin{array}{l}\text { Emigration rate for high- } \\
\text { skilled workers based on } \\
\text { Docquier and Marfouk } \\
\text { (2006) }\end{array}$ & $\begin{array}{l}\text { USA wage differential } \\
\text { relative to the other } \\
\text { countries: } \omega^{*}(1-\sigma) \varphi / \bar{\omega}\end{array}$ \\
\hline Yemen & YA & 6.0 & 15.45 \\
\hline Nigeria & NG & 10.7 & 14.85 \\
\hline Egypt & EG & 4.6 & 11.92 \\
\hline Haiti & HT & 83.6 & 10.31 \\
\hline Cambodia & $\mathrm{KH}$ & 18.3 & 7.45 \\
\hline Sierra Leone & $S L$ & 52.5 & 7.43 \\
\hline Ghana & $\mathrm{GH}$ & 46.9 & 7.12 \\
\hline Indonesia & ID & 2.1 & 6.72 \\
\hline Pakistan & PK & 12.6 & 6.57 \\
\hline Venezuela & VE & 3.4 & 6.57 \\
\hline Cameroon & $\mathrm{CM}$ & 21.2 & 6.53 \\
\hline Vietnam & $\mathrm{VN}$ & 27.1 & 6.49 \\
\hline India & IN & 4.3 & 6.25 \\
\hline Jordan & JO & 7.2 & 5.65 \\
\hline Ecuador & EC & 9.5 & 5.16 \\
\hline Bolivia & BO & 5.1 & 5.03 \\
\hline Sri Lanka & LK & 29.7 & 4.95 \\
\hline Nepal & NP & 5.3 & 4.85 \\
\hline Bangladesh & BD & 4.3 & 4.60 \\
\hline Uganda & UG & 35.6 & 4.38 \\
\hline Ethiopia & ET & 10.1 & 4.35 \\
\hline Guyana & GF & 89.0 & 3.87 \\
\hline Philippines & $\mathrm{PH}$ & 13.7 & 3.82 \\
\hline Peru & PE & 5.8 & 3.79 \\
\hline Brazil & BR & 2.2 & 3.76 \\
\hline Jamaica & JM & 85.1 & 3.63 \\
\hline Chile & $\mathrm{CL}$ & 6.1 & 3.53 \\
\hline Nicaragua & $\mathrm{NI}$ & 29.6 & 3.52 \\
\hline Panama & PN & 16.0 & 3.36 \\
\hline Uruguay & UY & 8.1 & 3.10 \\
\hline Guatemala & GT & 24.2 & 2.94 \\
\hline Colombia & $\mathrm{CO}$ & 10.4 & 2.88 \\
\hline Paraguay & PA & 3.9 & 2.78 \\
\hline South Africa & $\mathrm{ZA}$ & 7.5 & 2.75 \\
\hline Turkey & TR & 5.8 & 2.68 \\
\hline Argentina & AR & 2.5 & 2.54 \\
\hline Mexico & $\mathrm{MX}$ & 15.3 & 2.53 \\
\hline Belize & BZ & 65.5 & 2.43 \\
\hline Thailand & $\mathrm{TH}$ & 2.4 & 2.17 \\
\hline Costa Rica & CR & 7.2 & 2.07 \\
\hline Morocco & MR & 17.0 & 2.00 \\
\hline Dom. Republic & DO & 21.6 & 1.99 \\
\hline
\end{tabular}

Source: The data on skilled emigration rates are for the year 2000 and come directly from Table A.1-2, column 3 of Docquier and Marfouk (2006). The data on wage differentials between the U.S.A. and each of the listed countries are obtained from Table 1, column 6, of Clemens, Montenegro and Pritchett (2009). 
